\title{
Degradabilidad in situ de la Materia Seca y Proteína Cruda de las Hojas y Peciolo del Pisonay (Erythrina falcata)
}

\author{
In situ Degradability of Dry Matter and Crude Protein of Pisonay \\ (Erythrina falcata) Leaves ANd Petiole
}

\author{
Ludwing A. Cárdenas-Villanueva ${ }^{1}$, José L. Bautista-Pampa ${ }^{3}$, Jorge L. Zegarra-Pare- \\ des $^{4}$, Ruth Ramos-Zuniga ${ }^{5}$, Oscar E. Gómez-Quispe ${ }^{1,6}$, Juan S. Barreto-Carbajal ${ }^{2}$
}

\section{Resumen}

El estudio tuvo como objetivo determinar la composición química y la degradabilidad ruminal de la materia seca (MS) y proteína cruda (PC) del pisonay (Erythrina falcata) a los 105,120 y 135 días de rebrote. Se tomaron muestras de hojas y peciolo, se secaron y se colocaron $8 \mathrm{~g}$ de muestra molida por bolsa de nylon en el rumen de tres chivatos machos adultos por 0, 24, 48 y 72 horas. Los valores de MS y PC fueron 24.4 y $21.4 \%$ a los 105, 24.8 y $23.2 \%$ a los 120 y, 27.2 y $24.4 \%$ a los 135 días, respectivamente. La degradabilidad ruminal de la fracción insoluble potencialmente degradable de MS y PC fue 29.6 y $42.9 \%$ a los 105, 24.3 y $31.4 \%$ a los 120 y, 14.9 y $24.1 \%$ a los 135 días, respectivamente, y la degradabilidad efectiva de MS y PC fue 41.3 y $41.2 \%$ a los $105,36.5$ y $30.3 \%$ a los 120 y, 32.3 y $30.5 \%$ a los 135 días, respectivamente. El follaje de E. falcata a los 105 días de crecimiento posee una mayor ventaja proteica para los caprinos.

Palabras clave: fístula, ruminal, nutriente, follaje, caprino

\section{AbStract}

The study aimed to determine the chemical composition and ruminal degradability of dry matter (DM) and crude protein (CP) of Erythrina falcata at 105, 120 and 135 days of regrowth. Leaves and petiole samples were dried and $8 \mathrm{~g}$ of dry grounded samples were

\footnotetext{
${ }^{1}$ Facultad de Medicina Veterinaria y Zootecnia, ${ }^{2}$ Facultad de Ingenierías, Universidad Nacional Micaela Bastidas, Apurímac, Perú

${ }^{3}$ Facultad de Medicina Veterinaria y Zootecnia, Universidad Nacional del Altiplano, Puno, Perú

${ }^{4}$ Laboratorio de Nutrición y Alimentación Animal, Universidad Católica de Santa María, Arequipa, Perú

${ }^{5}$ Dirección Regional de Agricultura Puno, Ministerio de Agricultura y Riego, Perú

${ }^{6}$ E-mail: oegomezq@hotmail.com
}

Recibido: 14 de abril de 2015

Aceptado para publicación: 19 de setiembre de 2015 
placed in nylon bags in the rumen of three male goats during $0,24,48$ and 72 hours. The DM and CP values were 24.4 and 21.4\% at 105, 24.8 and $23.2 \%$ at 120 and, 27.2 and $24.4 \%$ at 105 days respectively. The ruminal degradability of potentially degradable insoluble fraction of DM and CP was 29.6 and $42.9 \%$ at 105, 24.3 and $31.4 \%$ at 120 and, 14.9 and $24.1 \%$ at 135 days, respectively, and the effective degradability of DM and CP was 41.3 and $41.2 \%$ at $105,36.5$ and $30.3 \%$ at 120 and, 32.3 and $30.5 \%$ at 135 days respectively. The study showed a higher protein advantage in goats at 105 days of growth of $E$. falcata foliage.

Key words: fistula, ruminal, nutrient, foliage, caprine

\section{INTRODUCCIÓN}

La necesidad de producir el alimento requerido por la creciente población mundial es un aliciente de importancia para la búsqueda y evaluación de estrategias que permitan incrementar la producción animal (García y Medina, 2006) como proveedora de alimentos. Toma especial importancia en este contexto el sistema silvo-pastoril, en donde se integra el manejo de especies arbóreas con las actividades agropecuarias, sin detrimento de los recursos naturales (Roa y Muñoz, 2012).

La producción ganadera en los valles interandinos del Perú presenta una serie de limitantes forrajeras en determinadas épocas del año. En estas regiones, los ganaderos y los comuneros cuentan con algunas especies forrajeras arbóreas, como las del género Erytrhina, que son empleadas para la alimentación animal como suplemento, siguiendo costumbres tradicionales, principalmente en épocas de secano donde el forraje es limitado.

Este grupo de forrajes comprende una gran diversidad y amplio rango de variación morfológica. Existen cerca de 115 especies descritas en diversas regiones del mundo (Pino-Rodriguez et al., 2004). Tienen un gran potencial para mejorar los sistemas de producción animal, debido a su mayor rendimiento de forraje respecto a las leguminosas herbáceas, mejor tolerancia al manejo, capacidad de rebrotar rápidamente, producción de forraje de buena calidad en condiciones de sequías prolongadas (Argel y Lascano, 1998), reducción de costos de alimentación, fuente de nutrientes como nitrógeno, energía, minerales y vitaminas (Urbano y Dávila, 2005), así como su adaptabilidad para ser utilizada como cercos vivos y como árboles de sombra para cultivos perennes (Russo, 1991), y que se constituyen como recursos renovables.

Entre estas especies se tiene a la Erythrina falcata (pisonay). Este es un árbol muy frondoso y con abundante follaje, que puede medir entre 3 a $20 \mathrm{~m}$ de altura y de 15 a $50 \mathrm{~cm}$ de diámetro (Reynel y Mercelo, 2009), el cual ha sido usado como forraje en la alimentación de algunas especies animales de granja. Se conoce que la mayoría de estas especies forrajeras contienen altos valores proteicos (Labrada et al., 2001; Pinto et al., 2004; Naranjo y Cuartas, 2011; Roa y Muñoz, 2012) que resultan promisorios para su aprovechamiento en la alimentación animal.

Por estas consideraciones, en el presente estudio se evaluó la cinética y la degradabilidad ruminal de materia seca y proteína cruda de hojas y peciolos del pisonay cosechadas a diferentes días de rebrote.

\section{Materiales y Métodos}

El experimento se realizó en la Universidad Nacional Micaela Bastidas, ubicado en el distrito de Tamburco, provincia de Abancay, departamento de Apurímac, Perú, a 2581 
metros de altitud. En esta zona, la temperatura máxima y mínima promedio anual es de 18 y $1.3{ }^{\circ} \mathrm{C}$, respectivamente, la humedad relativa varía entre 59 a $70 \%$ y la precipitación anual oscila entre 641 a 1119 mm/año.

Para determinar la composición químico proximal de materia seca (MS) y proteína cruda (PC) en hojas y peciolos de Erythrina falcata (pisonay), se recolectaron muestras de la región apical, media y basal de tres árboles de una misma parcela a los 105, 120 y 135 días de rebrote. El análisis de muestras se realizó en el Laboratorio de Nutrición y Alimentación Animal de la Universidad Católica Santa María de Arequipa, de acuerdo a lo propuesto por la AOAC (1990).

Se practicaron fístulas ruminales en tres chivatos adultos enteros (peso vivo de 75.0 $\pm 8.0 \mathrm{~kg}$ ). Las fístulas fueron de tipo permanente, de $5 \mathrm{~cm}$ de diámetro, con capacidad de suspender bolsas de nylon $(5 \times 10 \mathrm{~cm}$ de tamaño y $53 \pm 10 \mu \mathrm{m}$ de diámetro de poros) en el rumen. En los 30 días previos a la etapa de incubación de muestras y durante el periodo de evaluación, estos animales estuvieron al pastoreo en pastos con predominancia de Pennisetum clandestinum, Trifolium repens y Bromus unioloides, más una suplementación con hojas de Erythrina falcata $(2 \mathrm{~kg} / \mathrm{animal} / \mathrm{día})$ y agua ad libitum.

La degradación ruminal de la MS y PC se estimó por la técnica de digestión ruminal in situ, para lo cual se incubaron muestras de $8 \mathrm{~g}$ de forraje molido en bolsas de nylon en el rumen de animales fistulados (Ørskov et al., 1980) por 0, 24, 48 y 72 horas para cada uno de los días de rebrote. Los resultados fueron analizados con el modelo $\mathrm{P}=\mathrm{a}+\mathrm{b}(1-$ $\left.\mathrm{e}^{\mathrm{ect}}\right)$. La degradabilidad efectiva fue estimada por $\mathrm{DE}=\mathrm{a}+[(\mathrm{bxc}) /(\mathrm{c}+\mathrm{k})]$, siguiendo el procedimiento descrito por Ørskov y McDonald (1979), para lo que se asumió una tasa de pasaje (k) de 0.06/h (Michalet-Doreau et al., 1987). La fracción soluble (a), fracción degradable (b) y la tasa de degradación (c) se hallaron con el procedimiento RUMENAL (Correa, 2004).
En el análisis estadístico de la composición de MS y PC, los parámetros de la cinética ruminal y la degradabilidad, se empleó un diseño completamente al azar y para la comparación de medias se utilizó la prueba de rangos múltiples de Duncan, utilizando el Statgraphics v.16.

\section{Resultados}

La composición química proximal de $E$. falcata (Cuadro 1) indica que a medida que aumenta el tiempo de rebrote (de 105 a 135 días), la MS y la PC se incrementan en 2.8 y $3.0 \%$, respectivamente.

Entre los parámetros de la cinética ruminal de la MS y la PC (Cuadro 2) se tiene que, la fracción soluble (a) a los 135 días de rebrote fue de 24.6 y $17.6 \%$, respectivamente, y mejor que en los otros dos tiempos de rebrote. Asimismo, la fracción potencialmente degradable (b) de MS y PC fue 29.69 y $42.9 \%$, respectivamente, y la tasa de degradación (c) fue 8.9 y $9.8 \% / \mathrm{h}$ en MS y PC, al disminuir en ambos casos el tiempo de rebrote a 105 días en comparación con los otros tiempos de rebrote. Además, la tasa de degradabilidad efectiva (DE) fue superior (41.3\% en MS y $41.2 \%$ PC) a los 105 días respecto a 120 y 135 días del rebrote.

Cuadro 1. Composición químico proximal de materia seca (MS) y proteína cruda (PC) en hojas y peciolos de pisonay (Erythrina falcata)

\begin{tabular}{ccc}
\hline \multirow{2}{*}{$\begin{array}{c}\text { Edad de } \\
\text { rebrote } \\
\text { (días) }\end{array}$} & \multicolumn{2}{c}{ Componente $(\%)$} \\
\cline { 2 - 3 } & MS \pm d.e. & PC \pm d.e. \\
\hline 105 & $24.4^{\mathrm{b}} \pm 0.2$ & $21.4^{\mathrm{c}} \pm 0.6$ \\
120 & $24.8^{\mathrm{b}} \pm 0.2$ & $23.2^{\mathrm{b}} \pm 0.2$ \\
135 & $27.2^{\mathrm{a}} \pm 0.1$ & $24.4^{\mathrm{a}} \pm 0.1$ \\
\hline a,b Letras diferentes en una misma columna, \\
indican diferencias estadísticas $(\mathrm{p} \varangle 0.05)$
\end{tabular}


Cuadro 2. Cinética ruminal y degradabilidad efectiva (DE) de la materia seca (MS) y proteína cruda (PC) en hojas y pecíolos de pisonay (Erythrina falcata) para tres edades de rebrote

\begin{tabular}{ccccccc}
\hline Componente & $\begin{array}{c}\text { Edad de } \\
\text { rebrote } \\
(\text { días })\end{array}$ & $\begin{array}{c}\text { Valor de a } \\
(\%)\end{array}$ & $\begin{array}{c}\text { Valor de b } \\
(\%)\end{array}$ & $\begin{array}{c}\text { Valor de c c } \\
(\% / \mathrm{h})\end{array}$ & $\begin{array}{c}\text { Sin } \\
\text { degradar } \\
(\%)\end{array}$ & $\begin{array}{c}\text { Degradabilidad } \\
\text { efectiva } \\
(\% / \mathrm{h})\end{array}$ \\
\hline \multirow{3}{*}{ MS } & 105 & $23.6^{\mathrm{a}}$ & $29.6^{\mathrm{a}}$ & $8.9^{\mathrm{a}}$ & 46.8 & $41.3^{\mathrm{a}}$ \\
& 120 & $22.9^{\mathrm{a}}$ & $24.3^{\mathrm{a}}$ & $7.6^{\mathrm{b}}$ & 52.8 & $36.5^{\mathrm{b}}$ \\
& 135 & $24.6^{\mathrm{a}}$ & $14.9^{\mathrm{c}}$ & $6.5^{\mathrm{c}}$ & 60.5 & $32.3^{\mathrm{c}}$ \\
\hline \multirow{3}{*}{ PC } & 105 & $14.6^{\mathrm{a}}$ & $42.9^{\mathrm{a}}$ & $9.8^{\mathrm{a}}$ & 57.5 & $41.2^{\mathrm{a}}$ \\
& 120 & $13.0^{\mathrm{a}}$ & $31.4^{\mathrm{b}}$ & $7.4^{\mathrm{b}}$ & 44.1 & $30.3^{\mathrm{b}}$ \\
\hline
\end{tabular}

$a, b, c$ Letras diferentes en superíndices en una misma columna, indican diferencias estadísticas $(p \varangle 05)$. a: fracción soluble; b: fracción insoluble potencialmente degradable; c: tasa de degradación

\section{Discusión}

Los valores de MS (24.4 a 27.2\%) en hojas y peciolo de E. falcata del presente estudio fueron superiores a los reportados por Labrada et al. (2001) en E. variegata a diferentes edades de corte (promedio de 17.8\% y con valores de 18.1 a $19.4 \%$ en 30 a 90 días). Dichos resultados muestran claras diferencias de MS con la edad de corte, probablemente debido a la estructura de la hoja, que presenta un mayor tamaño y menor número de inervaciones en el rebrote. Asimismo, Naranjo y Cuartas (2011) obtuvieron $18.4 \%$ de MS con E. edulis, mientras que Roa y Muñoz (2012) encontraron 26.8\% de MS en pízamo (E. glauca), valor más cercano al del presente estudio, aunque no indican la parte muestreada del arbusto.

El 21.4 a $24.4 \%$ de PC encontrado entre los 105 a 135 días de rebrote resultaron valores próximos a otras especies arbóreas del mismo género. Así tenemos, $22.8 \%$ en $E$. goldmanii (Pinto et al., 2004), $23 \%$ en $E$. berteroana y $27 \%$ en E. variegata (Pedraza et al., 2003), 26.5\% en E. edulis (Naranjo y
Cuartas, 2011), 18\% en E. glauca (Roa y Muñoz, 2012) y 29.2 a $22.8 \%$ a los 30 y 90 días de rebrote en $E$. variegata (Labrada et al., 2001). Estos valores proteicos resultan ventajosos para el uso de esta especie arbustiva como suplemento para ganado al pastoreo en un sistema silvo-pastoril. Sin embargo, queda por determinar el uso adecuado en la dieta, ya que Almeida (2010) ha reportado la presencia de algunos compuestos activos, tales como alcaloides, flavonoides, taninos, glucósidos antraquinónicos y pequeñas cantidades de aceite esencial y saponinas.

En general, los niveles de MS y PC hallados en la presente investigación demuestran que la leguminosa arbustiva se caracteriza por aumentar su valor nutritivo con la edad de maduración de la planta. Al respecto, Olivares et al. (2005) indican que el comportamiento de la producción de MS comestible (hojas y tallos no lignificados) de las leguminosas arbustivas tiende a incrementar sostenidamente hasta alcanzar un máximo rendimiento y lograr una relación hoja-tallo satisfactoria, para luego declinar su producción de manera significativa donde predomina la presencia de tallos lignificados. 
Se tiene limitados estudios sobre la cinética ruminal de E. falcata; sin embargo, se dispone de información sobre otras especies del mismo género. En este contexto, Suchitra y Wanapat (2008) encontraron $40.3 \%$ en la fracción a, $30.8 \%$ en la fracción b y $0.059 \%$ en la fracción c en hojas de $E$. variegata, aunque no mencionan los días de rebrote utilizados para la evaluación.

La degradación efectiva de la MS disminuye al aumentar los días de rebrote, lo que demuestra que a través de los microorganismos ruminales se obtiene un mejor aprovechamiento de los nutrientes de E. falcata antes de los 120 días del rebrote. Asimismo, la digestibilidad estaría relacionada con la edad de corte. La mayor degradabilidad efectiva de la MS a los 105 días de rebrote $(41.3 \% / \mathrm{h})$ indica que la cantidad de energía que puede ser extraída del forraje durante el tiempo que permanece en el rumen será mayor, y está dado por la tasa de pasaje (k) del alimento hacia las partes más bajas del tracto digestivo. En estudios similares, pero con follaje de E. goldmanii, se encontró $57.83 \%$ de DE de la MS (Pinto et al., 2004).

La mayor degradación efectiva de la PC de E. falcata $(41.2 \% / \mathrm{h})$ se obtuvo a los 105 días de rebrote, disminuyendo con el tiempo de rebrote, lo cual podría deberse al aumento de la edad de la planta que ocasiona un incremento de la lignificación, dificultando el proceso de degradabilidad de la PC y disminuyendo su aprovechamiento. En otros estudios, Pinto et al. (2004) estimaron $62.2 \%$ de DE del follaje de $E$. goldmanii en vacunos, y Pedraza et al. (2003) estimaron $68.8 \%$ en $E$. variegata y $59.4 \%$ en $E$. berteroana, pero con $\mathrm{K}=0.05$.

\section{ConClusiones}

La degradabilidad ruminal de la fracción potencialmente degradable y degradabilidad efectiva de la Erythrina falcata tiene mejor ventaja nutricional de PC y MS a los 105 días que a los 120 y 135 días de rebrote.

\section{Literatura Citada}

1. Almeida EE. 2010. Caracterização farmacognóstica da espécie Erythrina falcata Benth., Fabaceae. Rev Bras Farmacogn 20(1): 100-105. doi: 10.1590/ S0102-695X2010000100020

2. [AOAC] Association of Official Analytical Chemists. 1990. Official methods of analysis. $15^{\text {th }}$ ed. Arlington, Virginia, USA: AOAC. 168 p.

3. Argel PJ, Lascano CE. 1998. Cratylia argentea (Desvaux) O. Kuntze: Una nueva leguminosa arbustiva para suelos ácidos en zonas subhúmedas tropicales. Pasturas Trop 20(1): 37-43.

4. Correa HJ. 2004. RUMENAL: procedimiento para estimar los parámetros de cinética ruminal mediante la función Solver de Microsoft Excel®. Rev Col Cienc Pec 17: 250-254.

5. García DE, Medina MG. 2006. Composición química, metabolitos secundarios, valor nutritivo y aceptabilidad relativa de diez árboles forrajeros. Zootecnia Trop 24: 233-250.

6. Labrada J, Guevara G, Estévez J, Martínez S, Pedraza R. 2001. Evaluación de algunos indicadores de la composición química del follaje de Erythrina variegata. Rev Prod Anim 13(1): 35-39.

7. Michalet-Doreau $B$, Vérité $R$, Chapoutot P. 1987. Méthodologie de mesure de la dégradabilité in sacco de lËazote des aliments dans le rumen. Bull Tech CRZV Theix 69: 5-7.

8. Naranjo JF, Cuartas CA. 2011. Nutritional characterization and ruminal degradation kinetics of some forages with potential for ruminants supplementation in the highland tropics of Colombia. Rev CES Med Vet Zootec 6(1): 9-19.

9. Olivares J, Jiménez $R$, Rojas $S$, Martínez PA. 2005. Uso de las leguminosas arbustivas en los sistemas de pro- 
ducción animal en el trópico. REDVET 6(5). [Internet]. Disponible en: http:// www.redalyc.org/articulo.oa?id= 63617216006

10. Orskov ER, DeB Hovell FD, Mould F. 1980. The use of the nylon bag technique for the evaluation of feedstuffs. Trop Anim Prod 5: 195-213.

11. Ørskov ER, McDonald I. 1979. The estimation of protein degradability in the rumen from incubation measurements weighted according to rate of passage. J Agric Sci Camb 92: 499-503.

12. Pedraza RM, La O O, Estévez J, Guevara G, Martínez, S. 2003. Nota técnica: degradabilidad ruminal efectiva y digestibilidad intestinal in vitro del nitrógeno del follaje de leguminosas arbóreas tropicales. Pastos y Forrajes 26: 237-241.

13. Pino-Rodriguez S, Prieto-González S, Pérez-Rodriguez ME, Molina-Torres J. 2004. Género Erythrina: fuente de metabolitos secundarios con actividad biológica. Acta Farm Bonaer 23: 252-258.

14. Pinto R, Gómez H, Martínez B, Hernández A, Medina F, Ortega L, Ramírez L. 2004. Especies forrajeras utilizadas bajo silvo-pastoreo en el cen- tro de Chiapas. Avances Invest Agropec 8(2): 1-11.

15. Reynel C, Marcelo J. 2009. Árboles de los ecosistemas forestales andinos. Manual de identificación de especies. Serie Investigación N. ${ }^{\circ}$ 9. Lima: Programa Regional Ecobona-Intercooperation. $163 \mathrm{p}$.

16. Roa M, Muñoz J. 2012. Evaluación de la degradabilidad in situ en bovinos suplementados con cuatro especies arbóreas. Rev MVZ Córdoba 17: 29002907.

17. Russo R. 1991. Erythrina (Leguminosae: Papilionoideae): a versatile genus for agroforestry systems in the tropics. J Sustain Agric 1(2): 89-109.

18. Suchitra K, Wanapat M. 2008. Study on ruminal degradability of local plants by using nylon bag technique. Livest Res Rural Develop 20. [Internet]. Disponible en: http://www.lrrd.org/lrrd20/ supplement/such1.htm

19. Urbano D, Dávila C. 2005. Leguminosas arbóreas para optimizar la producción de leche y carne. En: González C, Soto E (eds). Manual de ganadería doble propósito. Maracaibo, Venezuela: Fundación GIRARZ. p 213-218. 